\title{
La educación artística del estudiante superior de música: Diagnóstico mediante un estudio de revisión
}

\author{
The artistic education of the higher music student: \\ diagnosis through a review study
}

\begin{abstract}
Ana María Botella Nicolás, Universitat de València, España (ana.maria.botella@uv.es)
Guillem Escorihuela Carbonell, Institut Superior d'Ensenyances Artístiques, España

(d.escorihuelacarbonell@iseacv.gva.es)
\end{abstract}

\begin{abstract}
Resumen: La comprensión de la dimensión cultural y social de la obra de arte es indispensable en un profesional de la música, las disciplinas artísticas conviven y crean sinergias a lo largo de la historia. Se pretende determinar la situación actual de los centros españoles de enseñanzas artísticas superiores de música y el contacto del estudiante con las artes que le rodean, sabiendo que en su futuro profesional habrá de convivir y participar de ellas. La metodología de investigación está basada en una revisión sistemática de los planes de estudio de los conservatorios superiores de música de España. En todo el sistema de instituciones superiores analizadas sólo se ofrecen 44 asignaturas vinculadas al arte, de las cuales un 63,6\% son optativas. El estudio concluye que estamos ante una compartimentación de conocimientos, donde la práctica instrumental es el centro del currículum, dejando de lado los espacios de confluencia entre las artes.
\end{abstract}

Palabras clave: educación artística, conservatorios superiores de música, enseñanzas artísticas superiores, educación superior, arte.

Abstract: An understanding of the cultural and social dimension of the work of art is indispensable for a musician. It is intended to determine the current situation of the Spanish higher artistic music education institutions and the student's contact with arts that surround him, knowing that in his professional future he will have to coexist and participate in them. The research methodology is based on a systematic review of the study plans of the higher conservatories of music in Spain. In the entire system of higher institutions analyzed, only 44 subjects related to art are offered, of which $63,6 \%$ are optional. The study concludes that we are facing a compartmentalization of knowledge, where instrumental practice is the center of the curriculum, leaving aside the spaces of confluence between arts.

Keywords: artistic education, higher conservatories of music, higher artistic education, higher education, art. 


\section{Introducción}

El estudio de la cultura como patrimonio de producciones humanas y como expresión humana vinculada a la creación artística y la experiencia estética es considerada como herencia de los pueblos. La comprensión de la dimensión cultural y social de la obra de arte, como creación personal inmersa en un entorno cultural cercano o lejano, es indispensable en un profesional de la música o cualquier otro artista. La música es un arte que, como todos, se ha desarrollado de manera pura, pero también a través de muchas manifestaciones en colaboración con otras artes. De acuerdo con Botella y Escorihuela (2018): "la educación praxial en artes es un campo de controversia y de un alto grado de especificidad" (p. 78). Como tal, necesita de la presencia de un mediador entre el creador y el público al que va destinado el producto artístico. Este mediador es el intérprete (Botella y Escorihuela, 2014). Por ello, los estudios que abordan la educación musical del instrumentista deben de tener en cuenta la técnica instrumental basada en aspectos desarrollados a lo largo de la historia, pero también los conceptos y conocimientos que permitan al alumno la apreciación del valor estético. Sólo de esta manera, la ejecución del texto musical adquiere un significado y es capaz de transmitir la emoción del orden estético que despierta la obra musical en el espíritu del intérprete (Botella y Escorihuela, 2018).

Una actividad docente completa en el ámbito de la formación musical requiere una inmersión del alumnado hacia las competencias para entender, apreciar y ser capaz de crear el arte en diferentes expresiones culturales y artísticas. Todo ello, mediante el fomento de conocimientos, habilidades prácticas y actitudes que desarrollen un aprendizaje vinculado a la educación estética. Así pues, conocer las diversas manifestaciones culturales y artísticas constituye un trabajo esencialmente intelectual, favoreciendo el desarrollo de las iniciativas y la competencia comunicativa. En definitiva, tal y como indican Jiménez et al. (2009, s.p.): "la educación artística es una estrategia necesaria para el desarrollo de la sensibilidad, la creatividad y la visión estética de la vida que, junto con la dimensión ética, contribuye a la formación de ciudadanos cultos, tolerantes y solidarios". 
Bajo esta última premisa, este artículo, consciente de la necesaria sensibilización y enriquecimiento personal que supone una educación artística integral, se dispone a examinar el estado de dicha educación en el ámbito de los estudios superiores de música en España. Es cierto que muchos estudios como Hargreaves (1991) abordan la instrucción del arte dentro de las enseñanzas de régimen general, no obstante, hay un vacío en el conocimiento del magisterio del arte dentro de las propias enseñanzas artísticas.

Un artista, ya sea pintor, músico, escultor, poeta, bailarín, actor... debería entender y aplicar conocimientos de todas las disciplinas con las que, a través de su carrera artística, va a tener contacto. En el caso que nos ocupa, estamos hablando de contenidos propios de historia del arte, estética e historia de la música, conocimientos de antropología cultural, así como de los procedimientos de sinestesia entre música y otras artes. Bajo la hipótesis de que los planes de estudio dan crédito de la formación que adquiere el estudiante, y que un músico formado en una visión integral del arte será más competente, este artículo pretende investigar y reflexionar sobre la educación artística en el ámbito de los conservatorios superiores de música. Como dice Gutiérrez (2007), estos últimos son los encargados de preparar profesionalmente a sus alumnos, al mismo tiempo que se configuran como marcos culturales y educativos importantes para los músicos. Además, Gutiérrez (2007) añade:

Si, desde una perspectiva artística, se entiende por intérprete profesional a una persona que asume la responsabilidad de recrear y difundir la música como parte integral de la vida, reflejando en su interpretación el bagaje artístico, formación e influencia de su entorno a través de una ejecución de alto nivel, $[\ldots]$ habrá que poner un especial cuidado en su formación. (p. 12)

El titulado superior de música en España, ¿es capaz de argumentar los fundamentos teóricos de las diferentes corrientes interpretativas aplicadas a su repertorio instrumental en base a una formación artística? Esta investigación pretende visualizar un mapa del país que nos dé respuesta al tipo de educación artística que recibe el alumnado. Decisivamente, el músico formado en las artes con las que interactúa podrá poner en práctica todos sus recursos artísticos, estéticos, históri- 
cos y de juicio de gusto asimilados para abordar retos profesionales vinculados con la interpretación instrumental.

\section{Estado de la cuestión}

El arte, como realidad universal, forma parte de la cultura en todas las sociedades humanas pasadas y presentes. En su ecumenicidad, afecta a todas las personas, a todas las sociedades y a todas las culturas. No obstante, cada cultura posee unos parámetros propios para determinar qué es arte y valorarlo conforme a su ideario colectivo.

Por tanto, una definición de arte está sujeta a cada cultura, con soluciones tan variadas como culturas hay o ha habido. Posiblemente ninguna daría una definición sencilla, sino que estaría construida por un conjunto de características y condiciones.

Así pues, el fenómeno artístico está integrado por una serie de componentes semejantes que forman una estructura similar. De aquí la posibilidad de configurar una disciplina que lo estudie y esté basada en parámetros epistemológicos inequívocos.

Hoy en día nadie duda de la consideración de la música como arte, sin embargo, hay que tener en cuenta que:

(...) los antiguos griegos, que tenían distinciones precisas para tantas cosas, carecían de una palabra para lo que nosotros denominamos arte bello. La palabra que con frecuencia traducimos por «arte» era techné, la cual, lo mismo que la ars romana, incluía muchas cosas que hoy en día denominaríamos «oficio». (Shiner, 2004, p. 46)

Por tanto, el músico es un artista y debe sobrepasar lo mecánico y artesanal, para llegar a lo estético y espiritual. En la historia del arte hay momentos de ruptura entre el artesano y el artista, como dice Shiner (2004):

(...) durante el largo período helenístico (...) hay pruebas de que aparecen entre las clases altas actitudes y conductas semejantes a las nuestras y que éstas incluso sobreviven al triunfo del cristianismo. (...) También se dan en este período sorprendentes anticipaciones de las ideas y las prácticas modernas con relación a las artes visuales. Cuando los ejércitos romanos acabaron de saquear las estatuas y las vasijas de oro de Grecia, muchos romanos prominentes comenzaron a coleccionar y a 
encargar copias de las obras griegas. Algunos historiadores afirman que este coleccionismo (...) implica que tales obras eran ahora disfrutadas por ellas mismas, en tanto que obras de arte (...) El reconocimiento del cristianismo como religión oficial (...) reforzaron el carácter funcional de la poesía, la música y las artes visuales de tal modo que en Europa harían falta otros mil quinientos años para que se estableciese el moderno sistema del arte y de lo estético. (pp. 55-56)

Considerando la música un arte, la educación musical, desde un punto de vista integral, es la formadora del músico-artista y no de un mero ejecutor de partituras. Para ello se hace necesaria una educación artística que aborde todas las vertientes en las que pueda vincularse un estudiante de música. Entre las artes, la música ha tenido una curiosa relación con su entorno, la profundidad de esto ha implicado la invisibilización de este. Esta asemanticidad de la música se ha manifestado en la imposibilidad de sintetizar los significados a unidades de acepciones y estructurar un lenguaje o representación (Cabado, 2020).

En La formación artística y sus lugares, Ma Jesús Agra (2003) reflexiona acerca de las pocas oportunidades que el sistema educativo general ofrece para adquirir una formación mínima en relación con el arte. En su investigación la autora recoge impresiones de distintas facultades universitarias donde se reconoce abiertamente no tener conocimientos, no opinar por desconocimiento, ignorancia en el tema o formación nula.

Según Giráldez (2009), durante el pasado siglo la educación artística se ha guiado entorno a dos enfoques. El primero basado en una educación por el arte, y el segundo que se ha venido a denominar educación para el arte. La autora defiende esta segunda postura, ya que la primera es reduccionista en tanto que:

(...) las artes adquieren un papel subsidiario y sirven para otros fines más allá del propio desarrollo artístico del individuo, justificándose como vehículo de la expresión personal, como herramienta educativa en la transmisión de valores o como recurso para la enseñanza de otras materias donde las artes pueden servir de mediador. (p. 69)

Lejos de pensar en la aplicación de estos enfoques a una enseñanza generalista como hace la autora, los estudios superiores de música se distinguen por una alta especificidad, más si tenemos en cuenta los diferentes itinerarios que ofrecen los conservatorios y centros superiores españoles. 
La legislación española regula el contenido básico de las enseñanzas artísticas superiores de Grado en Música a través del Real Decreto 631/2010. En él se delimitan las especialidades que se pueden estudiar: Composición, Dirección, Interpretación, Musicología, Pedagogía, Producción y gestión y Sonología. Además, indica que las Administraciones educativas de cada Comunidad Autónoma son las que establecerán el plan de estudios en base a cada una de las materias establecidas en el real decreto, organizándose en una o varias asignaturas.

Las materias de Formación Básica son: Cultura, pensamiento e historia y Lenguajes y técnica de la música. La primera de ellas abarca los conocimientos fundamentales del hecho musical en relación con la cultura, desde el cariz histórico y sistemático, así como el análisis y la interpretación de los contextos sociales en que se produce este hecho. Y, de entre las materias obligatorias de especialidad de interpretación, destaca la Formación instrumental complementaria, que contempla la comprensión de la variedad de enfoques estilísticos y requerimientos asociados a la interpretación que le confieren un carácter flexible y adaptable a los estilos y tradiciones interpretativas. Además, a través de las asignaturas optativas que los centros ofrecen se acaba de perfilar el carácter de cada uno de ellos, con un alto grado de libertad para dirigir la enseñanza musical de sus alumnos.

En esta amalgama de asignaturas que se generan a partir del marco curricular, se debe dar la interacción entre las distintas disciplinas artísticas y la música. Según Ariza (2015), para poder observar esta concurrencia entre las artes habría que observar la capacidad de simbolismo y la intencionalidad de transmitir un mensaje. En este caso, el lenguaje toma relevancia, pero hay que tener en cuenta que no lo percibimos como una fuente de comunicación únicamente de vía oral, entenderemos también, por tanto, que la escritura forma parte de esta calidad del lenguaje. Esta, como grafía visual, es un medio por el que a través de símbolos obtenemos fonemas y distintas pronunciaciones orales.

El autor se pregunta si podemos enlazar la escritura con la música y la pintura, pues todas son disciplinas que se basan en la interpretación de signos para expresar algo. Por lo tanto, según Ariza (2015) podríamos considerar que en todos estos casos lo que se persigue es lo mismo: transmitir un mensaje. Es por este motivo 
por el que se considera que esta relación entre las artes está íntimamente ligada al sistema por el que un emisor (artista) representa un mensaje (obra), el cual es interpretado por el receptor (espectador) a partir de un código. A continuación, habría que concretar que este código viene condicionado a la época o contexto en que se desarrolla la acción, es decir, el momento en que es concebida la creación dispondrá las características de esta última. Y si atendemos a este esquema de comunicación, debemos tener en cuenta las teorías de la comunicación publicadas a partir del siglo XXI, que apuntan hacia una retroalimentación continua del emisor y el receptor, tal como apunta Baecker (2017). Para Novák (2021) la especificidad de cada una de las artes tiene un sistema distintivo de signos, y las estructuras equivalentes pueden concurrir así en diferentes artes, acentuando el aspecto visual (pintura), el aspecto auditivo (música) o una combinación de ambos aspectos (literatura).

A todo ello le es inmanente como elemento en común la creatividad, a la que Morales (2017) define como "la habilidad de producir un trabajo que es, a la vez, novedoso, original o inesperado, y apropiado, útil o adaptativo según la tarea” (p. 56). Esta conceptualización trata la creatividad desde una óptica cognitiva o potencial, pero Morales (2017) también incluye otras consideraciones que la conciben como un rasgo de la personalidad y parte de las relaciones interpersonales o la comunicación. Alrededor de todo este proceso de difusión, se crean las interrelaciones que justifican a lo largo de la historia la universalidad entre estas artes, siempre a partir de la intención de difundir ideas, pensamientos, creencias, ideales o sentimientos. La música es el arte que con más frecuencia ha buscado fusionarse con otros medios al ser en su estado puro la más ambigua de todas (Ariza, 2015).

En el caso de la literatura, ha convivido con la música desde la Antigüedad hasta hoy en día, confluyendo en multitud de obras como las tragedias griegas, la ópera, los dramas musicales, oratorios, etc. A lo largo del tiempo, los movimientos estéticos han abordado la relación entre música y literatura, desde las relaciones de complementariedad entre las dos artes, de intertextualidad o de necesidad, en la que una disciplina es evocada por la otra (López, 2013). Por su parte, la poesía ha seguido un camino paralelo a la literatura, más ligado si cabe. Música y 
palabra nacen de la mano, y se mantienen unidas durante la Antigüedad y la Edad Media $^{1}$, en ello influyó la importancia de la religión y su uso en los oficios. Así pues, es comprensible entender que la música vocal religiosa fuese considerada la más digna hasta prácticamente el siglo XVIII. La brecha entre literatura y música acaba por romperse en el Romanticismo, cuando filósofos y compositores elevan la música pura por encima de la vocal. A su vez, se desarrolla la obra de arte total con las aportaciones de Wagner, lo que impulsa dos corrientes antagónicas. El siglo XX supone una caída de los índices de consumo y producción de la música vocal culta, lo que provoca que la música absoluta surja como opción predilecta para el arte musical más intelectual, sin eludir los abundantes ejemplos de piezas programáticas o vocales (Ariza, 2015).

Por lo que respecta a las artes visuales, encontramos una relación casi de necesidad entre la música y el cine. Como dice Xalabarder (2006):

La música cinematográfica no consiste sólo en la mera aplicación de la música en una película, sino que puede participar de modo activo en su dinamización, explicación, ritmo e incluso aportación de elementos nuevos que el filme no dé por sí mismo pero que necesite. (p. 7)

Caso aparte ocupa la pintura, de compleja tilda De la Calle (2007) a la relación entre esta y la música:

El que las confrontaciones entre música y pintura no hayan sido ni mucho menos extrañas, a lo largo de la historia, y siga siendo aún una especie de reto recurrente, mantenido en el contexto de la cultura, el hecho de seguir intentándolo, una y otra vez, hace evidente que esa arriesgada operación de instaurar juegos de contrastes entre música y artes plásticas no deja de ser, cuando menos, escabrosa y complicada. (p. 91)

Autores como Kandinsky (1996), afirman que se establece una relación entre la pintura y la música. Este se postula a favor de que la primera debe avanzar hacia la abstracción mediante el color y la forma, utilizando únicamente los elementos de su propio lenguaje y no tomarlos de la naturaleza, al igual que la música

\footnotetext{
${ }^{1}$ Aunque encontramos abundantes ejemplos de música puramente instrumental desde la Antigüedad y en la Edad Media, la música vocal fue eminentemente más abundante y mejor valorada.
} 
utiliza los sonidos de la escala musical. En su teoría discurre que la forma, aunque sea abstracta y se reduzca a una forma geométrica posee un sonido interno y propiedades identificables a ella.

Lo bien cierto es que las artes visuales (pintura y escultura) y la música, han ido de la mano en gran parte de la historia de la Humanidad, también junto con la poesía. Tal y como indica Cárdenas (2015), si se toman como eje las relaciones interartísticas, se ha dedicado una especial atención a los contactos entre la lírica y la pintura. En el campo visual, lo ejemplifica mediante la inclusión de fragmentos poéticos en tratados artísticos, las referencias al arte del tapiz en literatos del Siglo de Oro o las muestras de 'tradición áurea' en fuentes icónicas de los siglos XVI y XVII.

Por lo que respecta a la escultura, autores como Labajo (1987), ya relacionan este arte con la música en el Renacimiento español a través del arte fúnebre, donde ambas se interrelacionan al servicio de lo perdurable y lo temporal, respectivamente.

La relación se vuelve más estrecha entre la música y las artes escénicas, en el caso de la interpretación del arte dramático, la música acompaña algunas de las escenas teatrales de las obras, por indicación del autor, o por indicación del director. En palabras de Gilabert (2017, p. 270): "El teatro europeo de la Edad Moderna integró la música vocal como uno de sus ingredientes básicos". No obstante, el campo que más entronca con la música es la danza. Shifres (2007) hace hincapié en cómo la sociedad occidental separó cuerpo y música desde los planteamientos de Pitágoras, pronunciándose más en la Edad Media, y llegando al punto álgido en el planteamiento dualista de Descartes. No obstante, el gesto musical ha seguido su curso, siendo un concepto recurrente en los textos musicológicos y en el lenguaje común de músicos y oyentes. La música constituye una acción sobre el cuerpo, siendo de importancia en la atribución de significado y, por tanto, el movimiento se convierte en clave para la producción y los procesos de comprensión musical. La danza, en su idiosincrasia necesita de la música para existir, aún sin sonidos, necesita del ritmo para coordinar el movimiento (Shifres, 2007). En el caso del ballet, destaca la interacción de música, pintura y danza que se crea alre- 
dedor de 1906, con la internacionalización de la música rusa, destacan autores como Mussorgsky, Rimsky-Korsakov, Borodin, Rachmarinov y Stravinsky. París se convierte en sede de la proyección del arte ruso, promovida y subvencionada por el empresario Serguei Diaguilev. Allí, se aglutinan algunos de los pintores rusos más destacados de finales del siglo XIX y principios del XX, como Roerich, Benois y Golovin, fortaleciendo la relación con los músicos, a través de la estrategia empresarial de Diaguilev (Sarriugarte, 2009).

La ópera es el cúmulo de muchas de estas artes, donde confluyen armoniosamente para dar vida a una historia, un argumento. Según Heinlein (1978):

Históricamente, la ópera constituye un conglomerado paradójico de espíritu retrospectivo y renovador. Los profesionales y aficionados que la inventaron alrededor de 1600 eran de la vanguardia de entonces, pero, al mismo tiempo, entusiastas partidarios de la idea renacentista, que deseaba reactivar culturas pretéritas. (p. 5)

Dice el autor, que se debe tratar la misma como teatro musical, tanto es así que autores como Gluck, Verdi y Wagner, persiguen lo mismo. Habla de una lucha desde el XVII entre texto literario y musical, y aboga por erradicar este antagonismo, ya que: "los propios compositores suelen ser los primeros en valorar la importancia del libreto y la puesta en escena" (p. 5). Se da el caso de que, los mismos músicos dramáticos se preocupan por los problemas del libreto, las cuestiones de realización escenográfica, de la vivacidad de la representación, en definitiva, de una obra escénica integrada.

\section{Metodología}

El presente texto es una revisión teórica que tiene por objetivo delimitar la enseñanza del arte en las aulas de los centros superiores música en España. Como propósitos secundarios se pretende demostrar la necesidad de una educación musical y artística holística, conocer la estructura organizativa y curricular de las instituciones superiores españolas de educación musical y comprobar el grado de adecuación de los currículos académicos a las competencias que la legislación educativa establece en este campo. Para ello, se han tenido en cuenta los planes de 
estudio de cada Comunidad Autónoma y el despliegue que cada centro puede desarrollar en base a su autonomía. Las búsquedas fueron realizadas en julio de 2020. Las bases de datos en las que se realizó la búsqueda fueron los sitios web de las Consejerías autonómicas que tienen transferidas las competencias sobre Enseñanzas Superiores Artísticas, los Boletines y Diarios Oficiales de cada Comunidad Autónoma, y los sitios web de los centros educativos. Teniendo en cuenta estas fuentes de información de carácter oficial, se han seleccionado las asignaturas cuya guía docente incluye estudios relacionados con otras artes. En concreto, esta investigación hace referencia a las asignaturas artísticas en los planes de estudio de la especialidad de interpretación en los itinerarios de instrumentos de la Orquesta sinfónica y piano, por ser los más comunes y demandados en estas enseñanzas. Las asignaturas que conforman el currículo de las Enseñanzas Superiores de Música y que se han visto reflejadas en la búsqueda de este estudio se han clasificado en dos categorías. La primera corresponde a las que ordenan las regulaciones autonómicas sobre planes de estudio y que afectan a todos los centros docentes del territorio. La segunda se dedica a las asignaturas optativas que cada institución, haciendo uso de su autonomía, puede ofrecer en su Programación General Anual.

La población para esta investigación está constituida por el conjunto de conservatorios superiores de toda España, tanto de enseñanza pública como privada. Para poder obtener el número total de conservatorios, hemos accedido a la información proporcionada por los servicios de Educación de las comunidades autónomas españolas. El curso seleccionado ha sido 2019/2020, en ese momento, el Estado Español contaba con 30 conservatorios y centros de enseñanza superior, que se encontraban repartidos en distinto número y ratio por las diferentes comunidades autónomas.

El análisis de datos utilizado se sustenta, desde una perspectiva cuantitativa, en el uso de frecuencias a través de términos de búsqueda en asignaturas. Desde el enfoque cualitativo, se ha analizado el contenido de la normativa autonómica que desarrolla los planes de estudio y el currículo del estudiante superior de música. 
Tabla 1

Centros Superiores de Música por Comunidad Autónoma

\begin{tabular}{|l|l|}
\hline Comunidad Autónoma & No $^{0}$ de Centros Superiores de Música \\
\hline Madrid & 6 \\
\hline Andalucía & 5 \\
\hline Comunidad Valenciana & 4 \\
\hline Galicia & 3 \\
\hline $\begin{array}{l}\text { Aragón, Canarias, Castilla y León, Castilla- } \\
\text { La Mancha, Extremadura, Islas Baleares, } \\
\text { Navarra, País Vasco, Principado de Astu- } \\
\text { rias y Murcia }\end{array}$ & 1 \\
\hline \begin{tabular}{l} 
Nota: elaboración propia \\
\hline
\end{tabular} & \\
\hline
\end{tabular}

\section{Resultados}

El Real Decreto 631/2010, por el que se regula el contenido básico de las enseñanzas artísticas superiores de Grado en Música establecidas en la Ley Orgánica 2/2006, de 3 de mayo, de educación, fue creado para "definir el contenido básico de planes de estudios conducentes a la obtención del Título de Graduado o Graduada en música, atendiendo al perfil profesional cualificado propio del ámbito de la música y de sus especialidades".

La propia legislación hace hincapié en promover el equilibrio entre los conocimientos conceptuales, el correcto desarrollo de la destreza técnica, la comprensión de los principios estéticos y culturales y la estimulación de la capacidad creativa, mediante el desarrollo de competencias transversales, generales y específicas según las necesidades fundamentales del ejercicio profesional. En este sentido, nuestro estudio aborda uno de los aspectos en el que el propio RD incide, de esta manera, también podremos comprobar la propia efectividad y aplicabilidad de la norma.

Analizando algunos de los artículos, encontramos conceptos e ideas de nuestro interés para este artículo. Según el artículo 3 (RD 631/2010), que trata la finalidad de las enseñanzas artísticas de Grado y su perfil profesional:

1. Las enseñanzas artísticas de grado en Música tendrán como objetivo general la formación cualificada de profesionales que dominen los conocimientos propios de la música y adopten las actitudes necesarias que les hagan competentes para integrarse en los distintos ámbitos profesionales de esta disciplina. 
2. El perfil del Graduado en Música corresponde al de un profesional cualificado que ha alcanzado la madurez y la formación técnica y humanística necesarias para realizar de manera plena la opción profesional más adecuada a sus capacidades e intereses, mediante el desarrollo de las competencias comunes a los estudios de Música y a la correspondiente especialidad. (p. 48482)

La organización de las materias, en base al artículo 7, se deja a cargo de las Administraciones educativas que, vista la propuesta de los centros, establecen el plan de estudios, completando hasta el total de 240 créditos los mínimos fijados en el Real Decreto. Para ello, tienen en cuenta que cada una de las materias se organice en una o varias asignaturas; que el plan de estudios se complete con otras materias, además de las establecidas en el RD y que se concreten en asignaturas; y que se establezcan asignaturas optativas que desarrollen contenidos cuya finalidad sea la de actualizar, completar o ampliar la formación del alumnado.

No obstante, se fijan unas materias vinculadas a la formación básica con un número de créditos asignado. En este caso, y si analizamos el Anexo I del RD 631/2010, observamos cómo se organiza en torno a dos materias: Cultura, pensamiento e historia y Lenguajes y técnica de la música. Por ello, nos fijaremos en la primera de ellas, común a todas las especialidades y que puede incluir el resto de las artes y sus teorías respecto a la música. En concreto, esta materia trata:

Conocimientos fundamentales del hecho musical en relación con la cultura, desde una perspectiva histórica y sistemática. Análisis e interpretación de los contextos sociales en que se produce este hecho. Integración de la investigación e interpretación de cara a una comprensión global del fenómeno de la práctica musical. (RD 631/2010, p. 48495)

Después de una búsqueda exhaustiva en todos los planes de estudio de las enseñanzas superiores de música en España, se han categorizado las asignaturas que abordan el arte. Posteriormente se han clasificado en tablas que comprenden la normativa autonómica, las asignaturas artísticas de la materia Cultura, pensamiento e historia, así como las optativas. 
Tabla 2

Centros Superiores de Música y normativa que regula el plan de estudios

\begin{tabular}{|c|c|}
\hline Centro & Normativa autonómica \\
\hline $\begin{array}{l}\text { CSM Rafael Orozco de Córdoba } \\
\text { CSM Victoria Eugenia de Granada } \\
\text { CSM de Jaén } \\
\text { CSM de Málaga } \\
\text { CSM Manuel Castillo de Sevilla }\end{array}$ & Decreto 260 , de 26 de julio de 2011 \\
\hline CSM de Aragón & Orden de 14 de septiembre de 2011 \\
\hline CSM Eduardo Martínez Torner de Oviedo & Decreto $40 / 2018$, de 26 de julio \\
\hline CSM de Castilla-La Mancha & Decreto $88 / 2014$, de $29 / 08 / 2014$ \\
\hline CSM de Castilla y León & Decreto $34 / 2013$, de 18 de julio \\
\hline $\begin{array}{l}\text { Escola Superior de Música de Catalunya } \\
\text { Centre Superior de Música Liceu }\end{array}$ & Decreto $85 / 2014$, de 10 de junio \\
\hline $\begin{array}{l}\text { Real CSM de Madrid } \\
\text { Centro de Enseñanza Musical Katarina } \\
\text { Gurska } \\
\text { Centro Superior de Enseñanza Musical } \\
\text { Progreso Musical } \\
\text { Escuela Superior de Música Reina Sofía }\end{array}$ & Decreto $36 / 2011$, de 2 de junio \\
\hline $\begin{array}{l}\text { CSM Oscar Esplà de Alicante } \\
\text { CSM Joaquín Rodrigo de Valencia } \\
\text { CSM Salvador Seguí de Castellón } \\
\text { ESMAR }\end{array}$ & Orden $24 / 2011$ de 2 de noviembre de 2011 \\
\hline CSM Bonifacio Gil de Badajoz & Decreto 28/2014, de 4 de marzo \\
\hline $\begin{array}{l}\text { CSM de A Coruña } \\
\text { CSM de Vigo } \\
\text { Centro Superior de Música de Galicia }\end{array}$ & Decreto $163 / 2015$, de 29 de octubre \\
\hline CSM de les Illes Balears & Decreto $4 / 2017$, de 13 de enero \\
\hline CSM de Canarias & Orden de 29 de abril de 2011 \\
\hline CSM Manuel Massotti Littel de Murcia & Resolución de 25 de julio de 2013 \\
\hline CSM de Navarra & Orden Foral 110/2010 \\
\hline $\begin{array}{l}\text { Musikene. Centro Superior de Música del } \\
\text { País Vasco }\end{array}$ & Decreto $368 / 2013$, de 25 de junio \\
\hline
\end{tabular}


Tabla 3

Centros Superiores de Música y asignaturas de Cultura, pensamiento e historia

\begin{tabular}{|c|c|}
\hline Centro & $\begin{array}{l}\text { Asignaturas de cultura, pensamiento e } \\
\text { historia }\end{array}$ \\
\hline $\begin{array}{l}\text { CSM Rafael Orozco de Córdoba } \\
\text { CSM Victoria Eugenia de Granada } \\
\text { CSM de Jaén } \\
\text { CSM de Málaga } \\
\text { CSM Manuel Castillo de Sevilla }\end{array}$ & $\begin{array}{l}\text { Historia de la música } \\
\text { Sociología y estética de la música }\end{array}$ \\
\hline CSM de Aragón & $\begin{array}{l}\text { Concepto histórico de la música } \\
\text { Historia y pensamiento contemporáneo }\end{array}$ \\
\hline CSM Eduardo Martínez Torner de Oviedo & $\begin{array}{l}\text { Historia de la música } \\
\text { Estética y filosofía de la Música }\end{array}$ \\
\hline CSM de Castilla-La Mancha & $\begin{array}{l}\text { Historia de la música } \\
\text { Sociología y estética musical }\end{array}$ \\
\hline CSM de Castilla y León & Historia de la música \\
\hline $\begin{array}{l}\text { Escola Superior de Música de Catalunya } \\
\text { Centre Superior de Música Liceu }\end{array}$ & $\begin{array}{l}\text { Música y cultura } \\
\text { Historia de la música } \\
\text { Estética de la música } \\
\text { Desarrollo profesional }\end{array}$ \\
\hline $\begin{array}{l}\text { Real CSM de Madrid } \\
\text { Centro de Enseñanza Musical Katarina Gurs- } \\
\text { ka } \\
\text { Centro Superior de Enseñanza Musical Pro- } \\
\text { greso Musical } \\
\text { Escuela Superior de Música Reina Sofía }\end{array}$ & $\begin{array}{l}\text { Teoría de la música } \\
\text { Historia del arte y estética } \\
\text { Historia de la música } \\
\text { Estética } \\
\text { Estética y filosofía de la música }\end{array}$ \\
\hline $\begin{array}{l}\text { CSM Oscar Esplà de Alicante } \\
\text { CSM Joaquín Rodrigo de Valencia } \\
\text { CSM Salvador Seguí de Castellón } \\
\text { ESMAR }\end{array}$ & $\begin{array}{l}\text { Historia de la música } \\
\text { Estética musical } \\
\text { Historia de la Música y del Pensamiento } \\
\text { Musical I y II } \\
\text { Teoría de la Interpretación }\end{array}$ \\
\hline CSM Bonifacio Gil de Badajoz & $\begin{array}{l}\text { Estética musical } \\
\text { Estética y crítica musical } \\
\text { Filosofía de la música } \\
\text { Historia de la música } \\
\text { Historia de la música contemporánea } \\
\text { Historia de la música electroacústica }\end{array}$ \\
\hline $\begin{array}{l}\text { CSM de A Coruña } \\
\text { CSM de Vigo } \\
\text { Centro Superior de Música de Galicia }\end{array}$ & $\begin{array}{l}\text { Historia de la música } \\
\text { Historia de la música gallega } \\
\text { Historia de la interpretación musical } \\
\text { Historia de la música iberoamericana }\end{array}$ \\
\hline CSM de les Illes Balears & $\begin{array}{l}\text { Historia de la música } \\
\text { Historia del pensamiento musical }\end{array}$ \\
\hline CSM de Canarias & Historia de la música \\
\hline CSM Manuel Massotti Littel de Murcia & $\begin{array}{l}\text { Historia de la música culta occidental } \\
\text { Estética y crítica musical contemporánea } \\
\text { Estética y crítica musical histórica }\end{array}$ \\
\hline CSM de Navarra & $\begin{array}{l}\text { Historia de la música } \\
\text { Estética y filosofía de la Música }\end{array}$ \\
\hline $\begin{array}{l}\text { Musikene. Centro Superior de Música del } \\
\text { País Vasco }\end{array}$ & $\begin{array}{l}\text { Historia de la música } \\
\text { Filosofía y estética de la música }\end{array}$ \\
\hline
\end{tabular}

Nota: elaboración propia 
Tabla 4

Centros Superiores de Música y asignaturas optativas

\begin{tabular}{|c|c|}
\hline Centro & Asignaturas optativas \\
\hline $\begin{array}{l}\text { CSM Rafael Orozco de Córdoba } \\
\text { CSM Victoria Eugenia de Granada } \\
\text { CSM de Jaén } \\
\text { CSM de Málaga } \\
\text { CSM Manuel Castillo de Sevilla }\end{array}$ & $\begin{array}{l}\text { Historia del arte } \\
\text { Historia del arte y cultura andaluza } \\
\text { Patrimonio musical andaluz y español }\end{array}$ \\
\hline CSM de Aragón & Historia del arte \\
\hline CSM Eduardo Martínez Torner de Oviedo & $\begin{array}{l}\text { Música de otras culturas } \\
\text { Música cinematográfica } \\
\text { Performance y escena contemporánea } \\
\text { Escena lírica I-II } \\
\text { Interpretación dramática }\end{array}$ \\
\hline \multicolumn{2}{|l|}{ CSM de Castilla-La Mancha } \\
\hline CSM de Castilla y León & $\begin{array}{l}\text { Arte, música y percepción } \\
\text { Dido y Eneas: texto, contexto y ecos }\end{array}$ \\
\hline $\begin{array}{l}\text { Escola Superior de Música de Catalunya } \\
\text { Centre Superior de Música Liceu }\end{array}$ & $\begin{array}{l}\text { Historia de la ópera } \\
\text { Música y danza }\end{array}$ \\
\hline $\begin{array}{l}\text { Real CSM de Madrid } \\
\text { Centro de Enseñanza Musical Katarina } \\
\text { Gurska } \\
\text { Centro Superior de Enseñanza Musical } \\
\text { Progreso Musical } \\
\text { Escuela Superior de Música Reina Sofía }\end{array}$ & $\begin{array}{l}\text { Latín aplicado a la música } \\
\text { La música y las otras artes } \\
\text { Historia del arte }\end{array}$ \\
\hline $\begin{array}{l}\text { CSM Oscar Esplà de Alicante } \\
\text { CSM Joaquín Rodrigo de Valencia } \\
\text { CSM Salvador Seguí de Castellón } \\
\text { ESMAR }\end{array}$ & $\begin{array}{l}\text { Encuentro entre las artes } \\
\text { Proyecto operístico I-IV }\end{array}$ \\
\hline CSM Bonifacio Gil de Badajoz & $\begin{array}{l}\text { Danzas históricas } \\
\text { Dramatización }\end{array}$ \\
\hline $\begin{array}{l}\text { CSM de A Coruña } \\
\text { CSM de Vigo } \\
\text { Centro Superior de Música de Galicia }\end{array}$ & $\begin{array}{l}\text { Coreografía y danza } \\
\text { Danza y baile tradicional de Galicia } \\
\text { Danza y baile tradicional general }\end{array}$ \\
\hline \multicolumn{2}{|l|}{ CSM de les Illes Balears } \\
\hline CSM de Canarias & $\begin{array}{l}\text { Danza y música en el mundo } \\
\text { Historia de la ópera }\end{array}$ \\
\hline CSM Manuel Massotti Littel de Murcia & Música e imagen \\
\hline CSM de Navarra & $\begin{array}{l}\text { Historia de la danza } \\
\text { Habilidades escénicas }\end{array}$ \\
\hline $\begin{array}{l}\text { Musikene. Centro Superior de Música del } \\
\text { País Vasco }\end{array}$ & \\
\hline
\end{tabular}

Nota: elaboración propia 
Tabla 5

Asignaturas vinculadas al arte

\begin{tabular}{|c|c|c|c|}
\hline Materias & Términos de búsqueda & $\begin{array}{l}\text { Resultados } \\
\text { totales }\end{array}$ & $\begin{array}{l}\text { Resultados } \\
\text { cribados }\end{array}$ \\
\hline $\begin{array}{lr}\text { Cultura, pen- } \\
\text { samiento } \\
\text { historia }\end{array}$ & $\begin{array}{l}\text { Historia, filosofía, estética, teo- } \\
\text { ría/pensamiento de la interpreta- } \\
\text { ción, sociología, cultura, arte críti- } \\
\text { ca }\end{array}$ & 44 & 15 \\
\hline Optativas & $\begin{array}{l}\text { Arte, patrimonio, cultura, cine, } \\
\text { escena, danza, ópera, drama, ima- } \\
\text { gen. }\end{array}$ & 28 & 9 \\
\hline
\end{tabular}

Nota: elaboración propia

La Tabla 5 es el resultado de convertir en frecuencias los términos de búsqueda de las asignaturas que se exponen en las tablas anteriores de Cultura, pensamiento e historia, y Optativas. Así pues, se observa que el 38,9\% de las asignaturas vinculadas al arte que el alumnado de Enseñanzas Artísticas Superiores de Música puede cursar a lo largo de sus estudios son optativas. Si se analiza por resultados cribados, en los que se han obviado las asignaturas repetidas, este porcentaje retrocede a un $37,5 \%$. Aún así, la mayoría de las que son obligatorias (62,5\% en datos cribados) son generalistas, como Historia de la música o Estética, y no abordan específicamente un tratamiento del arte.

\section{Conclusiones}

Entendemos por sinergia, aplicando el término al arte, a la suma de las distintas disciplinas para obtener un resultado mayor. Todos los centros superiores de música del Estado Español ofertan las asignaturas de la materia Cultura, pensamiento e historia, pero es difícil dilucidar hasta qué punto se consigue lo que el Real Decreto 631/2010 indica sobre los graduados en música:

Ser capaz de vincular la propia actividad musical a otras disciplinas del pensamiento científico y humanístico, a las artes en general y al resto de disciplinas musicales en particular, enriqueciendo el ejercicio de su profesión con una dimensión multidisciplinar. (p. 48489) 
Según nuestras indagaciones, esto sólo se ve reflejado en el apartado de optativas que, según normativa, son de elección voluntaria y sólo pueden cursarse un año. En la tabla nos limitamos a mencionar aquellas que se refieren a otras artes, y habría que destacar que en muchos de los centros no constan. No obstante, las asignaturas de historia del arte o de la ópera, son una clara evidencia de la formación global artística en distintas disciplinas.

Es importante destacar que esta sinergia entre las artes no es cosa de vanguardias, como se ha visto, las disciplinas artísticas han sido relacionadas a lo largo de la historia desde incluso antes de su concepción artística dentro de lo bello y el estudio estético. Como dice Puelles (2005, p. 173): “el arte (...) es una invención no anterior a la génesis histórica -a la producción cultural- de la actitud estética" y, por tanto, lo importante es el discurso, "no hay arte sin discurso; sin discurso y sin la confluencia de factores prácticos (...) capaces de dar génesis a ese producto cultural al que llamamos «arte moderno», causa y efecto de las bellas artes”.

Sin embargo, parece que asistimos a una compartimentación de los estudios artísticos. Donde, vistos los planes de estudios, la práctica instrumental toma el peso del currículum, pero descuida la sinergia que la propia música genera con las otras artes. Pese algún caso anecdótico, la asignatura Historia del arte que hasta la pasada ley educativa ${ }^{2}$ se podía ver en los planes de estudio, ha desaparecido. Y también adolecen nuestros centros de asignaturas que aborden desde la parte práctica, los retos de representar obras de arte de índole mixta, de poner en marcha proyectos con artistas de todo tipo. A esto se refieren Botella y Escorihuela (2018) cuando dicen que "los estudiantes deben aprender a interactuar con la música en múltiples situaciones" (p. 83).

Lo que es cierto, tal y como se ha visto en distintos autores, es que el análisis, disfrute y comprensión de las otras disciplinas artísticas, llevan al músico a una mayor sensibilidad, a un entendimiento mayor de su posición social, frente al arte y son generadoras de una ética artística y profesional. El debate que nos ocupa es si el músico debe nutrirse en sus estudios de la pintura, escultura, el actor, el escritor, etc., tal y como parece que indican los propósitos de la ley educativa, o si esto debe darse de forma autónoma.

\footnotetext{
${ }^{2}$ Ley Orgánica General del Sistema Educativo (LOGSE), de 3 de octubre de 1990.
} 
Esta idea se refuerza en diferentes ámbitos, no solo en el de la educación musical superior. Elichiry y Regatky (2010) ya reflexionan sobre el impacto de lo artístico-estético en la estructura del conocimiento en relación con el eje aprendizaje-cognición. Así pues, abogan por que los centros propicien el desarrollo del pensamiento creativo y reconocen en la experiencia artística una base importante para potenciarlo. Si lo que las autoras proponen para la escuela, lo extrapolamos a nuestros conservatorios superiores, toma mucha más fuerza, pues los diferentes lenguajes artísticos (visual/corporal/ musical/teatral) constituyen sistemas simbólicos culturales que promueven posibilidades de expresión y comunicación, en solitario, pero mucho más cuando interactúan entre sí como fenómenos dinámicos simultáneos.

De acuerdo con Martínez et al. (2015) "la división en áreas de conocimiento y en departamentos de las disciplinas artísticas ha supuesto una fragmentación tanto de su aprendizaje como de su propia concepción" (p. 179). Esto implica una brecha entre las artes, que se podría adelgazar a través de un trabajo competencial y una metodología interdisciplinar.

Las limitaciones de la investigación pasan por tener un acceso libre, directo y transparente a todas las guías docentes de las asignaturas, cuyo documento es esencial para delimitar el alcance de cada una de las disciplinas. No todas las instituciones analizadas tienen publicada esta información necesaria para llegar al último nivel de concreción curricular, así pues, han sido las descripciones de los planes de estudio y la normativa autonómica los escritos con los que han tenido que trabajar los investigadores. En base a esto, un estudio futuro podría incidir en una comparación entre el currículo y las guías docentes, además de un análisis entre estos y el campo profesional del intérprete, para así verificar las competencias artísticas que necesita o no en su entorno laboral.

Con todo ello, estas líneas vienen a reclamar un espacio de confluencia entre las artes, vistos los resultados desesperanzadores para el crecimiento artístico de nuestros estudiantes, las instituciones superiores de enseñanza musical deben propiciar ambientes de creatividad y no compartimentar la educación artística. Por tanto, este estudio concluye la necesidad de acercar al alumnado superior de música, especialmente el de los itinerarios de interpretación, al mundo de las artes en 
general, como recurso educativo, y a través del fomento de las artes visuales, la danza, la literatura y el uso del audiovisual. Incorporar todo este bagaje como herramientas de trabajo y aprendizaje. La manipulación de variados y diferentes materiales de carácter artístico de forma interactiva e integrada, permitirá el trabajo multi e interdisciplinar del alumnado, que podrá experimentar el hecho artístico de una manera global. Todo ello, a través de la intervención en la formación artística del alumnado desde múltiples perspectivas vehiculadas en diferentes asignaturas teóricas y/o prácticas.

\section{Referencias}

Agra, M. J. (2003). La formación artística y sus lugares. Educación artística. Revista de investigación, 1, 58-72. https://ojs.uv.es/index.php/eari/issue/view/179

Ariza, J. A. (2015). Niveles de afinidad entre la música, la pintura y la literatura. Un análisis comparativo en las tendencias del siglo XX. [Tesis doctoral no publicada]. Universidad de Málaga.

Baecker, D. (2017). Teorías sistémicas de la comunicación. Revista Mad. Revista del Magíster en Análisis Sistémico Aplicado a la Sociedad, 37, 1-20. https://doi.org/10.5354/0718-0527.2017.47267

Botella, A. M., \& Escorihuela, G. (2014). Análisis de la praxis docente de los profesores de las enseñanzas superiores de flauta travesera de la Comunidad Valenciana, El Artista, 11, 65-87.

https://www.redalyc.org/articulo.oa?id=87432695004

Botella, A. M., \& Escorihuela, G. (2018). Educación en artes: Un enfoque sobre la enseñanza performativa de la música. Revista Neuma, 11(1), 78-93. http://hdl.handle.net/10550/70124

Cabado, T. (2020). Música y realidad: hasta el concepto de música absoluta. Revista 4'33", 19, 152-161. http://revista433.damus.musica.ar/index.php/principal/article/view/15

Cárdenas, J. P. (2015). Artes hermanas: Poesía, música y pintura en el Siglo de Oro. Caliope: Journal of the Society for Renaissance and Baroque Hispanic Poetry, 20(2), 7-18. https://www.muse.jhu.edu/article/602323.

De la Calle, R. (2007). Sobre las relaciones entre música y pintura. AISTHESIS: Revista Chilena De Investigaciones Estéticas, 42, 87-97. http://ojs.uc.cl/index.php/RAIT/article/view/3390

Elichiry, N. E., \& Regatky, M. (2010). Aproximación a la educación artística en la escuela. Anuario de investigaciones, 17, 129-134. https://www.redalyc.org/pdf/3691/369139946072.pdf 
Gilabert, G. (2017). «I will play the swan and die in music». Shakespeare y Lope de Vega ante la música teatral trágica. Anuario Lope de Vega. Texto, literatura, cultura, 23, 270-285.

http://dx.doi.org/10.5565/rev/anuariolopedevega.199

Giráldez, A. (2009). Aproximaciones o enfoques de la educación artística. En L. Jiménez, Aguirre, I., y Pimentel, L. G. (Eds.), Educación artística, cultura y ciudadanía (pp. 69-74). Organización de Estados Iberoamericanos para la Educación, la Ciencia y la Cultura.

Gutiérrez, M. M. (2007). La formación de intérpretes profesionales en los conservatorios en el marco de la reforma educativa. Ministerio de Educación y Ciencia.

Hargreaves, D. J. (1991). Infancia y educación artística ( $3^{\mathrm{a}}$ ed.). Ediciones Morata.

Heinlein, F. (1978). Relación entre música y texto en el teatro musical del siglo XX. Revista Musical Chilena, 32(141), 5-16.

https://revistamusicalchilena.uchile.cl/index.php/RMCH/article/view/13534/1 $\underline{3811}$

Jiménez, L., Aguirre, I., \& Pimentel, L. G. (2009). Educación artística, cultura y ciudadanía. Organización de Estados Iberoamericanos para la Educación, la Ciencia y la Cultura.

Kandinsky, V. (1996). De lo espiritual en el arte (G. Dieterich, Trad.). Paidós.

Labajo, J. (1987). Música y escultura en el renacimiento español: interrelaciones al servicio del arte fúnebre. Boletín del Seminario de Estudios de Arte y Arqueología: BSAA, 53, 375-386.

https://dialnet.unirioja.es/servlet/articulo?codigo $=1959910$

López, E. (2013). Literatura y música. Brocar. Cuadernos de Investigación Histórica, 37, 121-143.

https://publicaciones.unirioja.es/ojs/index.php/brocar/article/view/2541

Martínez, S., Botella, A.M., Fernández, R., \& Mínguez, X. (2015). Música, artes visuales y literatura a través de la ópera. En N. Rius (Ed.), Investigación e Innovación en Educación Superior (pp. 179-184). PUV.

Morales, C. (2017). La creatividad, una revisión científica. Revista científica de Arquitectura y Urbanismo, 38(2), 53-62.

https://rau.cujae.edu.cu/index.php/revistaau/article/view/420

Novák, R. (2021). Transmedia principles in impressionism spanning painting, music and literature. Neohelicon, 48, 299-312. https://doi.org/10.1007/s11059-020-00558-7

Puelles, L. (2005). De cómo el arte se convirtió en el arte. Contrastes. Revista Internacional de Filosofía, 10, 169-176.

https://revistas.uma.es/index.php/contrastes/article/view/1896 
Sarriugarte, I. (2009). La fusión pintura, música y danza: la apuesta de Sergei Diaguilev. Música y educación: Revista trimestral de pedagogía musical, 22(77), 14-21.

Shifres, F. (2007). Poniéndole el cuerpo a la música. Cognición corporeizada, movimiento, música y significado. Actas de $3^{\circ}$ Jornadas de Investigación en Disciplinas Artísticas y Proyectuales (JIDAP). http://sedici.unlp.edu.ar/handle/10915/39368

Shiner, L. (2004). La invención del arte. Una historia cultural (E.H. Julibert, Trad.). Paidós.

Xalabarder, C. (2006). Música de Cine. Una ilusión óptica. Método de análisis y creación de bandas sonoras. Editorial Libros en red. 